\title{
EL GÉNERO CRYPTOCARYA (LAURACEAE) EN ARGENTINA
}

\author{
por SARA G. TRESSENS'
}

\section{Summary}

Cryptocarya R.Br. (Lauraceae) is reported for the first time for Argentina. Its differences with the other Argentinian genera are given. A description and an illustration of C. aschersonjana Mez are included.

\section{Introducción}

El objetivo de este trabajo es dar a conocer una novedad para la flora argentina en la familia Lauraceae Lindl. Se trata de una especie de Cryptocarya R.Br., género que no había sido mencionado para nuestro país.

Cryptocarya es un género pantropical con entre 200 y 250 especies (Kostermans, 1957; Vattimo, 1979b). Según Werf (1991) es un género pobremente conocido, que cuenta en el neotrópico con alrededor de diez especies, distribuidas en Brasil, Chile, Guayana Francesa, Venezuela, Ecuador y Perú.

La novedad tratada en el presente trabajo, Cryptocarya aschersoniana, fue descripta por Mez (1889) para Brasil donde se la conoce con los nombres vulgares de "canela-fogo", "canela de porco" y "canela-poruruca" (Reitz et al. 1978, Vattimo 1966, 1979b). Se describe e ilustra la especie para facilitar su reconocimiento y se detallan los caracteres que permiten diferenciar a Cryptocarya de los otros géneros de Lauráceas representados en Argentina.

\section{Material y Métodos}

Se utilizó la metodología clásica para trabajos taxonómicos. Se revisó material de los herbarios CTES y LIL. Para la descripción de

\footnotetext{
${ }^{1}$ Miembro de la Carrera del Investigador Científico del CONICET. Instituto de Botánica del Nordeste, UNNECONICET, Casilla de Correo 209, 3400 Corrientes, Argentina.
}

la especie se observaron ejemplares en su hábitat y se utilizó material de herbario y fijado en FAA. Las observaciones y dibujos se realizaron con microscopio estereoscópico Wild M3C y su correspondiente cámara clara.

\section{Resultados}

Hasta el momento habían sido citados para Argentina los siguientes géneros de Lauráceas: Cinnamomum Schaeff. (= Phoebe Nees), Nectandra Rol. ex Rottb., Ocotea Aubl. y Persea Mill. (Castiglioni, 1951; Subils, 1984). Con el hallazgo de C. aschersoniana se eleva a cinco el número de géneros de esa familia para nuestro país.

Cryptocarya se distingue fácilmente de los restantes géneros, por ser el único que presenta las anteras de los tres verticilos externos de estambres con 2 tecas y el tubo floral acrescente formando parte del fruto.

\section{Cryptocarya aschersoniana Mez}

Fig. 1

Mez, Jahrb. Königl. Bot. Gart. Berlin 5: 11. 1889.

Árbol de 6-15 $\mathrm{m}$ alt.; tronco de 4-5 $\mathrm{m}$ alt. $\mathrm{y}$ $\pm 25 \mathrm{~cm}$ diám.; corteza pardo-grisácea, delgada, escamosa, con escamas irregulares, fuertemente aromática; ramificación algo tortuosa; follaje denso, verde oscuro. Ramas glabras, castaño-rojizas, lenticeladas; ramas jóvenes más oscuras, con lenticelas escasas o ausentes. Ápices vegetativos áureo-pubescentes. Yemas 


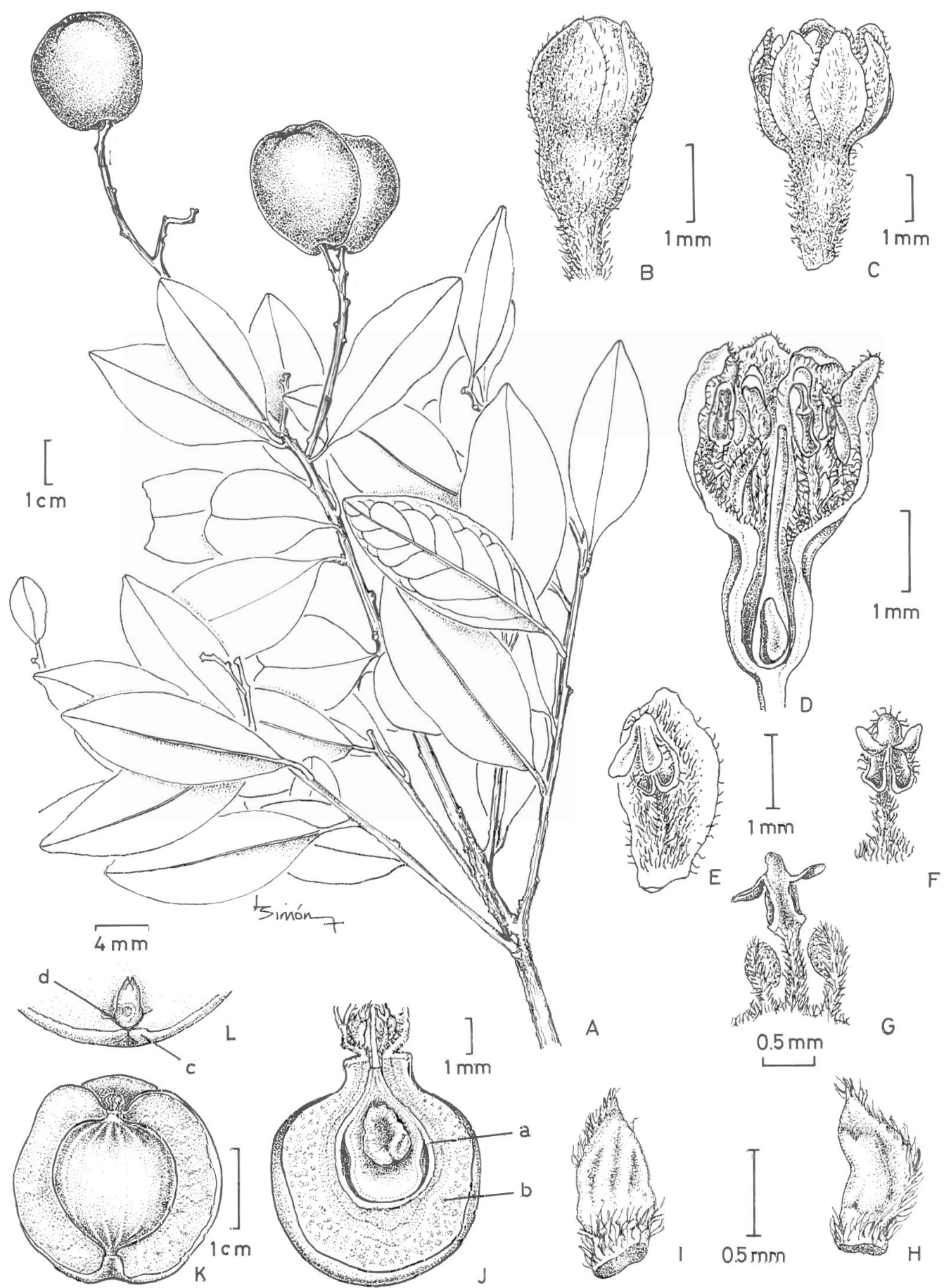

Fig. 1. Cryptocarya aschersoniana: A, rama con frutos; B, alabastro; C, flor; D, corte longitudinal de la flor; E, estambre del verticilo I y tépalo externo, vista ventral; F, estambre del verticilo II, vista ventral; $G$, estambre del verticilo III con glándulas basales, vista dorsal; $H$, estaminodio, vista lateral; I, estaminodio, vista ventral; J, corte longitudinal del fruto en desarrollo, a: pared del ovario, b: tubo floral; K: corte longitudinal del fruto maduro, porción leñosa entera; L, detalle del embrión mostrando la base de la cara adaxial de un cotiledón, la plúmula y la radícula, c: lóbulos del cotiledón, d: radícula (A, Tressens et al. 5604; B-J, Tressens et al. 5684; K-L, Tressens et al. 5693). 
axilares con escamas coriáceas, ovales, agudas, glabras o pubescentes en el ápice y la vena media. Hojas fragantes, alternas; adultas glabras, las jóvenes pubescentes en el pecíolo, margen de la lámina e hipofilo sobre la vena media. Pecíolo 5-10 mm long., cara adaxial canaliculada. Lámina coriácea o subcoriácea, algo discolora, con diminutos puntos glandulares, 3-9,5 cm long. x 1,2-3,7 cm lat., elíptica o angustielíptica; ápice agudo, brevemente acuminado u obtuso; base aguda; margen entero; epifilo nítido; hipofilo algo más claro; venación pinnada, 6-12 venas secundarias por semilámina, prominentes en el hipofilo; vena marginal notable, amarillenta en vivo al igual que la vena media; venación menor formando un denso retículo de pequeñas aréolas. Tirsos paniculiformes, terminales o axilares en los extremos de las ramas, 2,2-9 cm long.; ejes ferrugíneo-tomentosos; brácteas triangulares, caducas, ca. $1 \mathrm{~mm}$ long., adpreso-tomentosas. Pedicelos breves, tomentosos. Flores perfectas, 3-5 mm long., verde pálidas, tomentulosas por fuera con indumento más denso hacia la base. Tubo floral elipsoidal, 1,5-2 mm long., contraído por encima del ovario dejando un angosto canal donde se encuentra el estilo; garganta densamente pubescente. Tépalos 6, subiguales, elípticos u ovado-elípticos, agudos a obtusos, interiormente adpreso-pubescentes. Estambres inclusos, en verticilos trímeros, 9 fértiles y 3 estaminodios. Estambres fértiles con filamentos densamente pubescentes; anteras 2-tecas, con puntos glandulares, $\pm 1 \mathrm{~mm}$ long.; dehiscencia valvar; conectivo prolongado en un apéndice notable, obtuso. Estambres de los dos verticilos externos algo incurvos; filamentos tan largos como las anteras o más breves, adnatos a los tépalos en la porción basal; anteras ovadas u ovadooblongas, ciliadas, introrsas; apéndice conectival ciliado. Estambres del tercer verticilo erectos; par basal de glándulas subglobosas, con un notable pie pubescente; filamentos estaminales de igual o mayor longitud que las anteras; anteras angustiovadas, glabras, laterales o extrorso-laterales; apéndice conectival glabro. Estaminodios ovado-agudos, $\pm 1 \mathrm{~mm}$ long., pubescentes dorsalmente, filamento breve, pubescente. Gineceo glabro, ca. $3 \mathrm{~mm}$ long.; ovario elipsoide, 1-1,5 mm long., en- vuelto por el tubo floral, pero no soldado a él; 1 óvulo péndulo; estilo cilíndrico; estigma inconspicuo. Fruto drupáceo, amarillo o amarillo-verdoso a la madurez, 1,6-3,2 cm long. $x$ 1,7-2,8 cm lat., depreso-globoso u obovoide; ápice brevemente prolongado en el fruto inmaduro, con las piezas florales persistentes que dejan al desprenderse un rodete algo rugoso; porción carnosa originada del tubo floral acrescente, ca. $5 \mathrm{~mm}$ espesor, blanquecina, esponjosa y con secreción mucilaginosa en el fruto maduro; porción leñosa derivada del interior del tubo floral y de la pared del ovario, lisa o con costillas poco prominentes, depresoglobosa, obovoide o elipsoide, atenuada en la base, umbonada en el ápice. Semilla globosa, 10-15 mm diám., cubierta delgada, pardo-rojiza, suavemente 4-costulada; embrión con plúmula y radícula pequeñas y cotiledones grandes, macizos, plano-convexos, rectos, de contorno casi circular, con pequeños lóbulos basales que cubren por completo a la radícula; restos de endosperma de consistencia gelatinosa entre los cotiledones.

Vattimo (1979b) señala que la madera es dura y difícil de aserrar y que en Brasil es usada para viguería en general y es apreciada para laminados.

Material examinado: ARGENTINA. Misiones. Dpto. Gral. Manuel Belgrano: Ruta 101 y Salto Andresito, 29-III-1996 (fr), Tressens et al. 5604 (CTES); ídem, 11-XII-1996 (fl y fr inmaduros), Tressens y Maruñak 5684 (CTES); ídem, 20-III-1997 (fr), Tressens et al. 5693 (CTES).

BRASIL. Paraná. NW de Laranjeiras do Sul, 23IX-1969 (fI), Klein \& Eskuche 01751 (CTES); Bôa Vista (mun. Guaratuba), 25-X-1984 (fl), Hatschbach 48552 (CTES); Rio do Cobre (mun. Palmital), 15-X1991 (fl), Hatschbach 55766 \& Silva (CTES); Bocaina (mun. Bocaiuva do Sul), 25-I-1974 (fr), Hatschbach 33771 (CTES). Rio Grande do Sul. Farroupilha, 29I-1949 (fr), Rambo 40290 (LIL).

\section{Distribución geográfica y observaciones ecológicas}

Coe--Teixeira (1965) y Vattimo $(1966,1978$, 1979a y b) han citado esta especie para los Estados de Minas Gerais, Rio de Janeiro, São Paulo, Paraná, Santa Catarina y Rio Grande do Sul. Las localidades más occidentales registra- 
das se encuentran en los Municipios Palmital y Laranjeiras do Sul (Paraná). En Brasil crece tanto en la "mata pluvial" de la costa atlántica, como en la del interior en los planaltos, en la de Araucaria y en la "mata latifoliada" de la cuenca del río Uruguay, a alturas que van de 10 a 1100 m s.m. (Coe-Teixeira 1965, Vattimo 1979b, Reitz et al. 1978).

En Argentina fue hallada en la provincia de Misiones, conviviendo con otras Lauráceas (Nectandra y Ocotea) y con Araucaria, en la selva marginal higrófila del arroyo Gramado, afluente del Urugua-í Grande, a una altura de $685 \mathrm{~m}$ s.m., en suelo rojo sobre basalto. Se presenta con mayor abundancia en el borde inundable de la barranca del arroyo. Durante las observaciones realizadas en el período de fructificación, se encontraron abundantes frutos caídos; debajo de los árboles alejados del curso de agua, se observaron algunos frutos con la porción carnosa aparentemente comida por animales, así como pequeñas plantas. También se hallaron numerosos frutos flotando en el agua, procedentes de los árboles que crecen en la orilla, lo que sugiere que podrían ser transportados por ese medio.

Obs. Kostermans (1937) trata a Cryptocarya aschersoniana bajo C. moschata Nees et Mart. ex Nees. En el presente trabajo se sigue el criterio de Vattimo (1966, 1979b) quien mantiene a ambas especies separadas, basándose en diferencias morfológicas observadas "in vivo", así como en las condiciones ecológicas en que crecen ambas entidades. Esta autora distingue a C. aschersoniana por el fruto subliso o con costillas casi obsoletas, de color amarillo limón, con el exocarpo desprendiéndose con facilidad al ser comprimido entre los dedos y las hojas con retículo venoso diminutamente areolado y poco prominente; las plantas crecen en suelos planos de formación más o menos aluvional, arenosos o en los márgenes de ríos. Caracteri- za a C. moschata por sus frutos conspicuamente costulados, amarillos o anaranjados, con el exocarpo más resistente y las hojas con retículo prominente; crece en lugares donde predominan los suelos más secos y pobres.

\section{Agradecimientos}

A la Secretaría General de Ciencia y Técnica de la UNNE por el apoyo económico brindado para la realización de los viajes de campaña, al Sr. Víctor Maruñak por su valiosa colaboración en el trabajo de campo y a la dibujante Laura Simón por la elaboración de las ilustraciones .

\section{Bibliografía}

CASTIGLIONI, J. A. 1951. Lauráceas argentinas. I. Género Nectandra. Bol. Soc. Argent. Bot. 4(1-2): 66-94, figs. 16.

COE-TEIXEIRA, B. 1965. Lauráceas do Estado de São Paulo - II: Cryptocarya. Arq. Bot. Estado São Paulo 4 (1): 3-9, tab. 1.

KOSTERMANS, A. J. G. H. 1937. Revision of the Lauraceae II. The genera Endlicheria, Cryptocarya (American species) and Licaria. Recueil Trav. Bot. Néerl. 34: 500609 , figs. $1-5$.

— 1957. Lauraceae. Reinwardtia 4 (2): 193-256.

MEZ, C. F. 1889. Lauraceae Americanae. Jahrb. Königl. Bot. Gart. Berlin 5: 1-556, taf. 1-3.

REITZ, R., R. M. KLEIN \& A. REIS. 1978. Projeto madeira de Santa Catarina. Sellowia 28-30 (30): 1-320, est. 1-88.

SUBILS, R. 1984. Lauraceae, en A. Hunziker (ed.), Los géneros de Fanerógamas de Argentina. Bol. Soc. Argent. Bot. 23 (1-4): 172.

VATTIMO, I. DE. 1966. Notas sôbre o gênero Cryptocarya R. Br. no Brasil (Lauraceae). Rodriguésia 25 (37): 219 237, figs. $1-78$.

— 1978. Contribuição ao conhecimento da distribuição geográfica das Lauraceae I. Rodriguésia 29 (44): 269 305.

— 1979a. Contribuição ao conhecimento da distribuição geográfica das Lauraceae V. Rodriguésia 31 (50): 37-65. -1979b. Lauráceas, en Reitz, Flora llustrada Catarinense, LAUR: 1-50, figs. 1-7.

WERF, H. VAN DER. 1991. A key to the genera of Lauraceae in the New World. Ann. Missouri Bot. Gard. 78 (2): 377-387, figs. 1-2. 